\title{
Efeito de filmes ativos biodegradáveis de acetato de celulose, incorporados com poligalacturonase, na manutenção da turbidez de suco de laranja Pera.
}

\author{
CRUZ, L. F.1; SILVA, M. L. C. ${ }^{2}$; \\ 1. Graduando em Engenharia de Alimentos, Universidade Estadual de Feira de Santana, e-mail: \\ lislandialis@ hotmail.com \\ 2. Orientadora, Departamento de Tecnologia, Universidade Estadual de Feira de Santana, e-mail: \\ marilialordelo@yahoo.com.br
}

\section{PALAVRAS-CHAVE: poligalacturonase; acetato de celulose; clarificação INTRODUÇÃO}

A laranja é um produto muito importante para a agricultura e economia do brasileiro. A categoria que representa o maior volume vendido comercialmente no Brasil é a de bebida não alcoólica, que apresentou maior crescimento tanto em termos totais quanto per capita. Sendo a categoria de sucos prontos, beneficiada por uma tendência de valorização de alimentos funcionais, estando o mercado de suco e néctares o que mais cresceu e cresce com alta de $100 \%$ de 2004 a 2008. Em todo o mundo, no setor agroindustrial, a indústria de sucos de frutas é uma das maiores, sendo o suco de laranja o produto com maior destaque (TRIBESS, 2003; VENTURINI FILHO, 2011).

Nos sucos cítricos a turbidez é uma propriedade importante para a aceitação do consumidor. A turbidez é decorrente da extração do suco da laranja, pois esse processo provoca ruptura das células, gerando uma mistura de partículas em suspensão contendo lipídios, proteínas, pectina, celulose e hemicelulose. O elemento que estabiliza naturalmente a turbidez dos sucos cítricos é a pectina, pois ela age como emulsificante que ajuda a manter a suspensão das partículas. A principal enzima na composição do suco de laranja é a pectinesterase ou pectina esterase (EC 3.1.1.11), conhecida também como pectase, pectina metoxilase ou pectina metil-esterase.

A pectinesterase desesterifica a pectina em suco fresco ou subpasteurizado. Esta enzima age sobre a pectina de alta metoxilação do suco de laranja e a modifica em pectina de baixa metoxilação liberando metanol e $\mathrm{H}+$, cátion hidrogênio diminui o $\mathrm{pH}$ do meio. A pectina de baixa metoxilação livre pode ser hidrolisada pela enzima poligalacturonase (EC 3.2.1.15) ou complexar com o $\mathrm{Ca}++$ presente no suco e precipitar, perdendo assim a turbidez, afetando a qualidade do suco, a sua aparência, diminui o sabor e aroma natural e aumentando também a sensibilidade a oxidação. A poligalacturonase hidrolisa de forma aleatória as ligações glicosídicas internas entre os resíduos de ácidos galacturônicos, provocando a despolimerização da molécula (CORRÊA NETO, 1999; DA SILVA, 1997; TRIBESS, 2003).

É vantajoso o uso de enzimas em processos de tecnologia de alimentos, pois elas são específicas e para ocorrer reação não necessitam de temperaturas elevadas e nem formam produtos indesejáveis, dentre outros motivos (DA SILVA, 1997). É uma área inovadora o desenvolvimento da tecnologia de embalagem ativa para produção de suco de laranja não clarificado.

O presente trabalho teve como objetivo avaliar a eficiência da enzima poligalacturonase incorporada em filme de acetato de celulose para evitar a clarificação do suco de laranja. 


\section{MATERIAL E MÉTODOS OU METODOLOGIA (ou equivalente)}

- Preparação das filmes:

Foram confeccionados três tipos de filmes. Os filmes de acetato de celulose tiveram concentrações de $0,05 \%$ e $0,1 \%$ da enzima poligalacturonase. $O$ filme de acetato de celulose controle (FACC) que foi batizado como A, para melhor simplificação no momento de identificar, o qual não colocou-se a enzima poligalacturonase; o filme de acetato de celulose com 0,0015 gramas de poligalacturonase (FACPG 0,05), batizado como B e o filme de acetato de celulose com 0,0030 gramas de poligalacturonase (FACPG 0,1) batizado como C.

Identificou-se os três pote de acordo com a concentração da enzima, sendo A o controle; B e C com as concentrações de $0,05 \%$ e $0,1 \%$. Em seguida retirou-se a enzima da geladeira e pesou-se 0,0015 e 0,0030 gramas, e transferiu-se para dois dos três potes já identificados (B e C), contendo a solução filmogênica feita anteriormente. Com ajuda do bastão de vidro foi feita a homogeneização da enzima nos potes $\mathrm{B}$ e $\mathrm{C}$ com a solução filmogênica. Teve-se o cuidado de limpar o bastão após homogeneização do pote $B$, para não transferir substância para o pode C. Logo, os potes foram fechados e deixados em repouso para que as bolhas de ar formadas na solução sumissem, para não prejudicar a elaboração dos filmes. Enquanto isso, com o bastão de vidro já limpo enrolou-se nas extremidades do bastão a fita crepe, dando um total de dez voltas em cada extremidade, para dar a espessura desejada aos filmes. Com as soluções já livres de bolhas, despejouse cuidadosamente na placa de vidro a solução do pote A e puxou-se lentamente com o bastão de vidro, e esperou-se 15 minutos para evaporação do solvente. $\mathrm{O}$ mesmo foi feito com as soluções dos potes $\mathrm{B}$ e $\mathrm{C}$ em placas de vidro distintas, sendo que estas demoravam um pouco mais de 15 minutos para secar, devido as enzimas presentes nas soluções filmogênicas. Quando secos os filmes foram retirados das placas e identificados como A, B e C.

Com os filmes secos, cortou-se amostras de $(5 \times 1) \mathrm{cm}^{2}$. Colocou-se o molde em baixo de uma placa de vidro transparente e por cima da placa de vidro, colocou-se o filme elaborado, fixando-o com fita crepe, e com ajuda de um estilete foram feitos os cortes. Após cortado os filmes foram posto de placas de petri e levados para a cabine de luz ultravioleta, ficando cerca de 15 minutos cada lado do filme, para ser feita a sua esterilização. As amostras dos filmes esterilizados, foram transferidos para os tubos Falcon (esterilizado na autoclave) identificados também de acordo com o filme contido nele. O processo também foi dentro da cabine, mas utilizando somente a luz branca, pois a luz ultravioleta é nociva para o ser humano. Logo os tubos Falcon foram armazenados dentro da geladeira a $10^{\circ} \mathrm{C}$ até que o suco de laranja fosse preparado.

- Preparação do suco de laranja:

Foi feita a higienização das laranjas (cerca de 12 laranjas) e utensílios em solução clorada de 200ppm durante 15 minutos e em seguida enxaguados em água corrente. $\mathrm{O}$ suco de laranja foi extraído, utilizando-se espremedor doméstico e deixado em banho de gelo, para que as atividades das enzimas fossem menos favorecida. Em seguida foi feita a pasteurização do suco. Numa panela com água fervendo, foi colocado submerso o erlenmeyer contendo o suco de laranja, com um termômetro imerso no suco de laranja, para o controle da temperatura, que deve ser de $60^{\circ} \mathrm{C}$ durante 10 minutos. Para não desnaturar as características sensoriais do suco, foi feito um tratamento térmico brando. Após pasteurização o suco voltou para o banho de gelo. Quando o suco estava frio transferiu-se para 4 potes de centrifugação, para ser feita a separação da polpa, ainda em banho de gelo. Então o suco foi retirado do banho de gelo e levado para a centrifuga, a 
$30 \mathrm{rpm}$ (velocidade de rotação) durante 10 minutos. Saindo da centrifuga o suco foi novamente posto em banho de gelo, e levado para a cabine (esterilizada), juntamente com os filmes ativos contido nos tubos Falcon estéreis. Então foram transferidos $13 \mathrm{~mL}$ do suco de laranja para cada tubo Falcon estéreis, feito isso o tubos voltaram novamente para a geladeira.

- Leitura da transmitância do suco de laranja:

Após cinco dias de armazenamento foi feita a leitura da transmitância do suco de laranja. Utilizando o espectrofotômetro no modo transmitância e empregando o comprimento de onda de 660, pois é o mais apropriado para sucos. Inicialmente calibrou-se o espectrômetro no modo transmitância com água destilada, a transmitância da água deve ser de $100 \%$. Em seguida foram feitas as leituras de transmitância dos sucos contidos nos tubos Falcon, retirando uma alíquota de $3 \mathrm{~mL}$ e transferindo para a cubeta e anatando-se os resultados para em seguidas fazer as análises.

\section{RESULTADOS E/OU DISCUSSÃO (ou Análise e discussão dos resultados)}

A Figura 1 apresenta os resultados de transmitância para os diferentes tratamentos ao longo do tempo. Pode-se observar que os tubos contendo filme (com e sem enzima) apresentaram valores de transmitância menores do que os tubos sem filme. $\mathrm{O}$ filme de acetato de celulose sem enzima (FACC), manteve a turbidez do suco mais alta do que a do o suco sem filme. Isso pode ser pela presença de hidroxilas no polímero se ligam aos íons de cálcio presente no meio, evitando a formação de pectato.

No entanto, dentre os tratamentos com filme, o valor de transmitância foi maior para o tratamento FACCPG0.1, que continha a maior quantidade de enzima, ou seja, a turbidez final foi menor quanto maior foi a quantidade de enzima. Esse resultado não era esperado, pois esperava-se que a enzima poligalacturonase evitasse a precipitação de pectato de cálcio, pela hidrólise de ácidos poligalacturônicos. Isso pode ser decorrente do tipo de extrato bruto, que contém outras enzimas que interferiram no processo. Por outro lado, o filme de acetato de celulose, manteve a turbidez do filme mais alta do que o suco sem filme. Isso pode ser pela presença de hidroxilas no polímeros que podem sequestrar os cálcio presente no meio, evitando a formação de pectato. Os desvios para todos os ensaios foram considerados elevados, indicando que existem interferentes que não foram controlados no experimento.

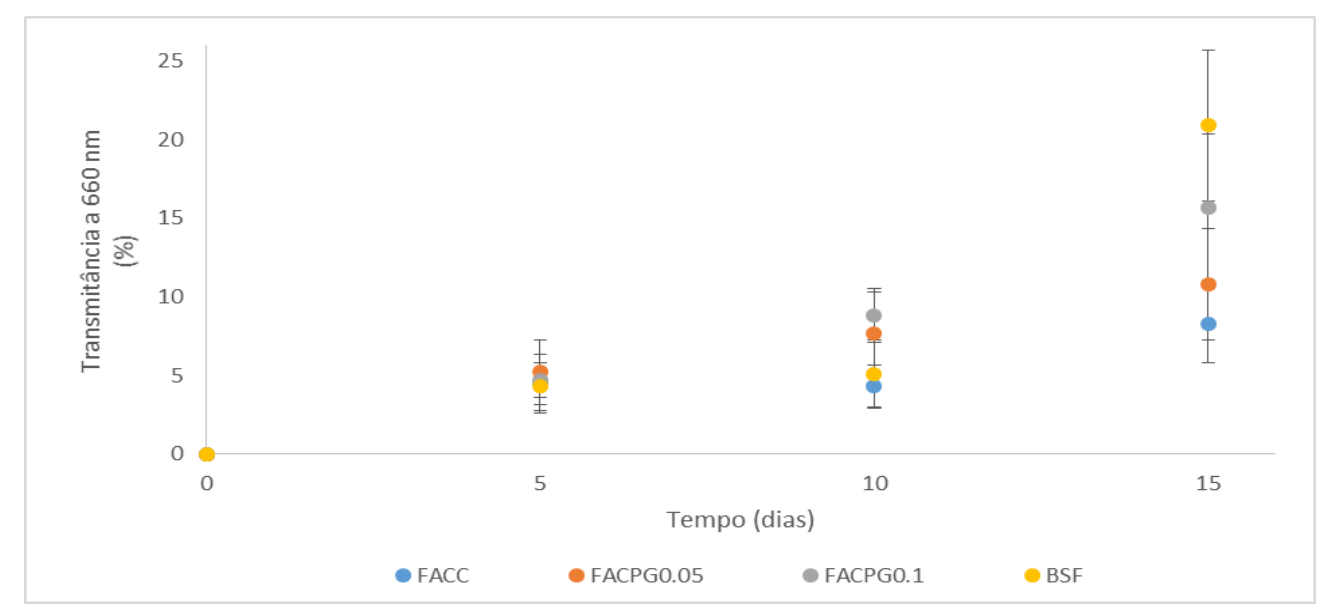

Figura 1: Transmitância versus tempo nos diferentes tratamentos estudados. 


\section{CONSIDERAÇÕES FINAIS}

O presente trabalho possibilitou estudar o efeito de filmes de acetato de celulose na manutenção de turbidez de suco de laranja. Os achados sugerem que o extrato bruto enzimático utilizado não apresenta pureza suficiente para garantir que a atuação da poligalacturonase seja eficiente. Assim, a tendência observada não estava de acordo com o esperado, sugerindo que novas pesquisas devam ser realizadas a fim de investigar os fatores que influenciaram nesses resultados.

\section{REFERÊNCIAS}

AZEREDO, H. M. C. 2012. Fundamentos de estabilidade de alimentos. 2. ed. rev. ampl. Brasília, DF: Embrapa, 326 p.

CORRÊA NETO, R. S. 1999. Fatores que influem na qualidade do suco de laranja. UNICAMP/FEA. Departamento de Tecnologia de Alimentos, Campinas, São Paulo.

CUNHA, L. R. et. al. 2007. Desenvolvimento e avaliação de embalagem ativa com incorporação de lactase. Ciênc. Tecnol. Alimentos, Campinas, São Paulo, p.23-26, ago.

DANIELE, F. et. al. 2009. Determinação de vitamina C em amostras de suco de laranja in natura e amostras comerciais de suco de laranja pasteurizado em embalagem Tetra Pak. Ver Ciência Saúde. [S.L.:s.N.].

KOBLITZ, M. G. B. 2015. Bioquímica de Alimentos: Teoria e Aplicações Práticas. Rio de Janeiro: Guanabara Koogan.

MOURA, L. E. 2013. Desenvolvimento de filmes bioativos de polietileno de baixa densidade e eficácia antioxidante e antimicrobiana como embalagem de produtos lácteos. 122 f. Dissertação (Mestre em Ciência de Alimentos). Faculdade de Farmácia, Universidade Federal da Bahia, Bahia.

OLIVEIRA, T. M de et. al. 2008. Uso de embalagem ativa na inibição do escurecimento enzimático de maçãs. Semina: Ciências Agrárias, Londrina, v. 29, n. 1, p. 117-128.

SILVA, R. et. al. 1997. Pectinases, hemicelulases, e celulases, ação, produção, e aplicação no processamento de alimentos: revisão. Departamento de Química e Geociências IBILCE/UNESP, São José do Rio Preto, São Paulo, p. 249-260.

TRIBESS, T. B. 2013. Estudo da cinética de inativação térmica da pectinesterase em suco de laranja natural minimamente pasteurizado, p.117. Dissertação (Mestre em Engenharia Química). Departamento de Engenharia Química, Escola Politécnica da Universidade de São Paulo, São Paulo.

VENTURINI FILHO, W. G. 2011. Indústria de Bebidas: inovação, gestão e produção. 1. ed. São Paulo: Blucher, v. 2. 